\title{
The importance of leaders' characteristics in community capacity building for tourism development
}

\begin{abstract}
The purpose of the study is to assess the importance of leaders' characteristics and their economic interest in community capacity building for tourism development. The information for this study was derived from survey questionnaires. The respondents were community leaders from Shiraz. The findings through multiple regression analysis indicate that approximately 74 percent $\left(\mathrm{R}^{2}=.737\right)$ of the variance $\mathrm{CCB}$ for tourism development was predicted by the leaders' income, income from tourism, extra activities, length of residency, educational level, and family engaged in tourism industry. According to the results, the largest beta coefficient is the leaders' income through tourism $(\beta=.350)$. It is expected that the findings could be utilized by community developers for future reassessment in tourism planning.
\end{abstract}

Keyword: Community leaders; Community capacity; Tourism development 